\title{
Solid type primary intraosseous squamous cell carcinoma in the maxilla: report of a new case
}

\author{
Mitsuyoshi lino ${ }^{1 *}$, Shigeo Ishikawa ${ }^{1}$, Hisashi Ozaki ${ }^{1}$, Takehito Kobayashi ${ }^{1}$, Hirohiko Tachibana', \\ Hiromasa Sakurai ${ }^{1}$ and Noriaki Kikuchi ${ }^{2}$
}

\begin{abstract}
Background: Primary intraosseous squamous cell carcinoma is a rare jaw bone tumor defined as squamous cell carcinoma arising within the jaw, having no initial connection with the oral mucosa and developing from residual odontogenic epithelium or from an odontogenic cyst or tumor. Solid type of this tumor arising in the maxilla is an even rarer presentation, because the majorities derive from cystic lesions and are found in the posterior mandible.

Case presentation: A 36-year-old Japanese man was referred to our clinic with a complaint of pain around the anterior maxillary region on the right side. Intraoral examination identified a firm, non-fluctuant mass with no ulceration in the vestibular region of teeth \#11-13. Incisional biopsy was performed, leading to histological diagnosis of moderately differentiated squamous cell carcinoma. Contrast-enhanced computed tomography revealed a destructive tumor with no cystic lesion, $>50 \mathrm{~mm}$ in diameter. There was no evidence of metastatic disease on chest radiography, upper gastric endoscopy or positron emission tomography. Based on these findings, solid type primary intraosseous squamous cell carcinoma was diagnosed. The patient underwent tumor ablative surgery. The surgical defect was reconstructed using a partially double-folded free radial forearm flap and prefabricated denture-based surgical obturator. The postoperative course was quite good. Neither recurrence nor metastasis had been found as of 3 years and 1 month postoperatively.
\end{abstract}

Conclusion: To the best of our knowledge, the present case represents only the 10th case of solid type primary intraosseous squamous cell carcinoma arising in the maxilla to be reported.

Keywords: Primary intraosseous squamous cell carcinoma, Solid type, Maxilla

\section{Background}

Primary intraosseous squamous cell carcinoma (PIOSCC) is a rare jaw bone tumor defined as a squamous cell carcinoma (SCC) arising within the jaw, having no initial connection with the oral mucosa, and, presumably, developing from residual odontogenic epithelium or from an odontogenic cyst or tumor [1]. PIOSCC is classified into solid type, derived from keratocystic odontogenic tumor, and derived from odontogenic cysts [1]. The majority of PIOSCCs are found in the posterior mandible and derived from a cystic lesion [2-7]. Solid type PIOSCC arising in the maxilla is thus an even rarer presentation [2-7]. We present herein a new case of

\footnotetext{
*Correspondence: m-iino@med.id.yamagata-u.ac.jp

'Division of Dentistry, Oral and Maxillofacial Surgery, Faculty of Medicine, Yamagata University, 2-2-2 lida Nishi, Yamagata City Yamagata 990-9585, Japan

Full list of author information is available at the end of the article
}

successfully treated solid type PIOSCC of the anterior maxilla.

\section{Case presentation}

A 36-year-old man was referred to our clinic from his family dentist with a complaint of pain around the anterior maxillary region on the right side. The patient's medical history was non-contributory. Intraoral examination identified a firm, non-fluctuant mass with no ulceration in the vestibular region between the right upper central incisor and canine (Figure 1). The right upper central and lateral incisors were missing. A computed tomography (CT) showed severe bony resorption between the right upper second premolar and the left upper lateral incisor (Figure 2). Incisional biopsy was performed via vestibular approach. The specimen of the tumor was extirpated with overlying mucosa. During the biopsy, an intact cortex was not observed. The

\section{Biomed Central}




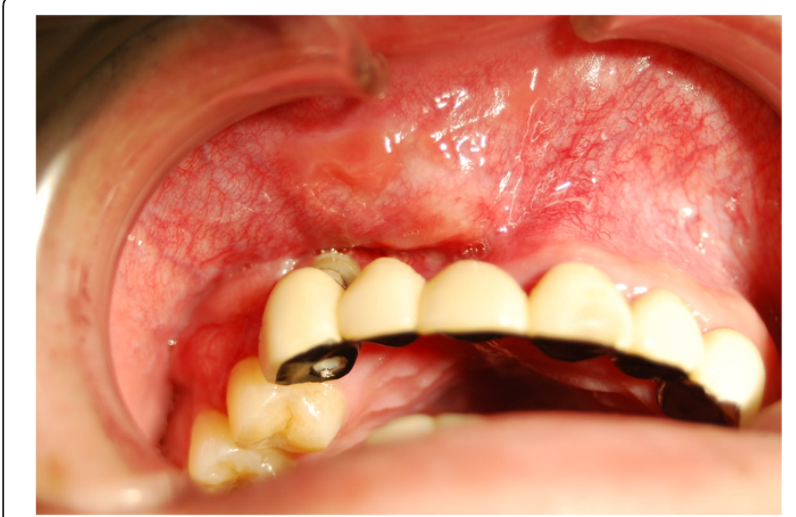

Figure 1 Intra-oral view at first visit, showing a firm and non-fluctuant submucosal swelling of the anterior maxilla.

histological diagnosis was moderately differentiated SCC. The connection between the tumor and the overlying mucosa was not observed. Contrast-enhanced computed tomography (CE-CT) revealed a destructive tumor with no cystic lesion, $>50 \mathrm{~mm}$ in diameter. The tumor pressed the skin around the nasal ala and the nostril of the right side, but no direct connection between the skin and tumor was observed. Although the maxillary sinus and nasal cavity were deformed by the tumor, no abnormal findings were seen for the mucosa of the nasal cavity and maxillary sinus (Figure 3). One swollen and enhanced lymph node was recognized in the submandibular area of the right side. Positron emission tomography (PET) revealed the enhanced lesion in the maxilla and the right submandibular area. There was no evidence of metastatic disease on chest radiography, upper gastric endoscopy or PET. Based on these findings, solid type PIOSCC was diagnosed.

The patient underwent tumor ablative surgery. After bilateral supraomohyoid neck dissection, the primary

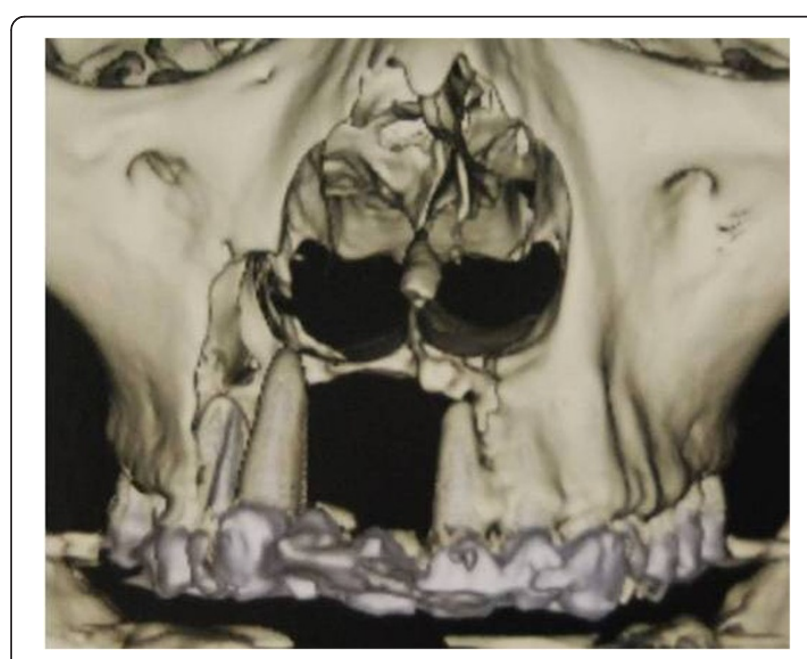

Figure 2 3D-CT showing severe bony resorption between the right upper second premolar and the left upper lateral incisor.

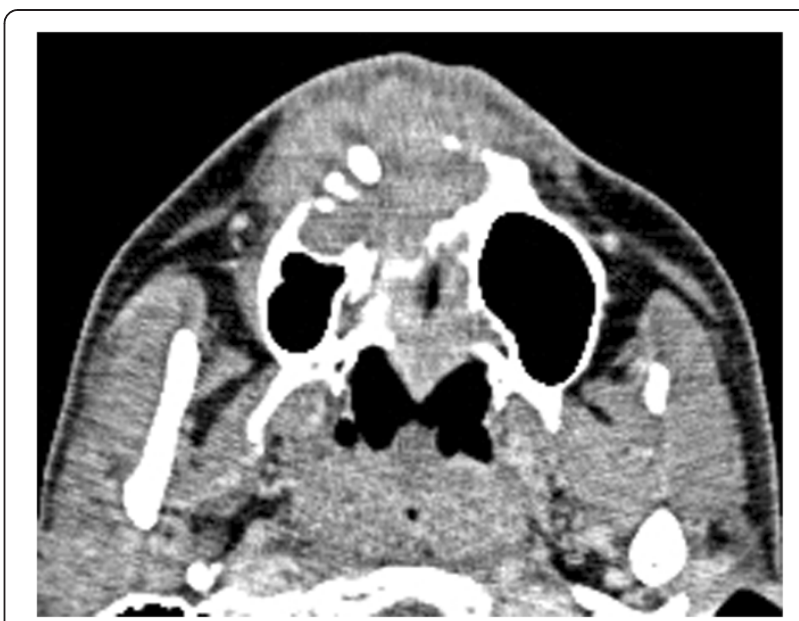

Figure 3 Preoperative CE-CT showing a large, destructive tumor located in the maxilla.

tumor was radically excised. The surgical specimen comprised the anterior two-thirds of the hard palate and nasal septum, bilateral inferior nasal conchae and the skin around the nasal ala and nostril of the right side. The surgical defect was reconstructed using a partially double-folded free radial forearm flap and prefabricated denture-based surgical obturator. Microscopic examination of the surgical specimen revealed SCC without cystic component in the maxillary bone. The islands of the tumor cells extended into the bone (Figure 4) with no dysplasia or carcinoma in the skin and mucosa of the nasal cavity and maxillary sinus. The dissected surgical specimen of the neck showed one lymph node metastasis of the ipsilateral submandibular region. Although adjuvant radiotherapy was recommended, the patient declined additional treatment. The postoperative course was quite good. Neither recurrence

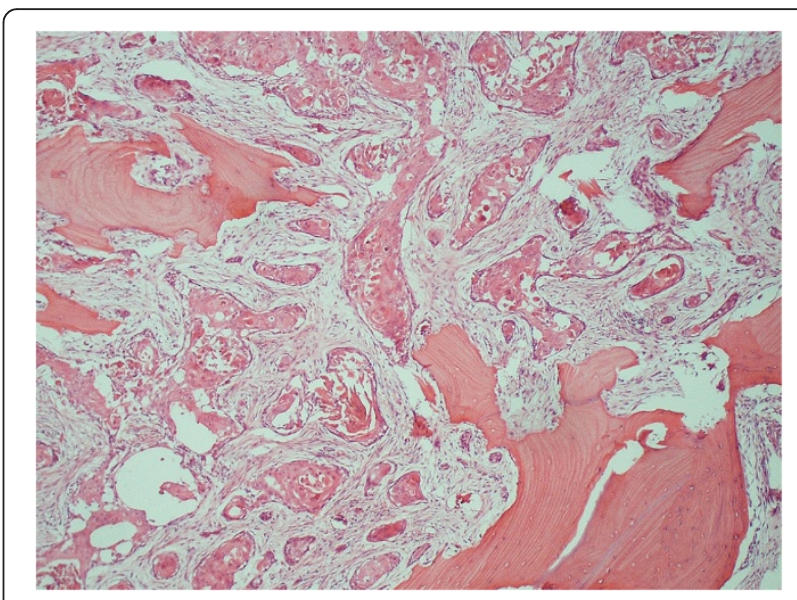

Figure 4 Photomicrograph of the resected maxilla showing the moderately differentiated SCC. The islands of the tumor cells extended into the maxillary bone. 
nor metastasis had been found as of 3 years and 1 month postoperatively.

\section{Conclusions}

The diagnostic criteria for PIOSCC include absence of an initial connection with the overlying mucosa or skin and exclusion of metastasis from a distant primary tumor by physical and radiographic examination during a follow-up period of at least 6 months [2]. As the present case fulfilled all the criteria listed above and contained no cystic component, this tumor represented solid type PIOSCC in the maxilla. This tumor is thought to arise by direct malignant transformation of odontogenic epithelial rests such as remnants of dental lamina, and reduced enamel epithelium surrounding unerupted/impacted teeth [8]. In this case, the teeth \#11 and 12 were removed before the first visit. Therefore, some aberrant epithelial tissue including the rests of Malassez is also the possible origin.

In a review of 200 cases reported up to 2010, Nomura et al. [7] reported only eight cases (4\%) of solid type PIOSCC in the maxilla. In 2011, Mohyuddin and Yao [9] reported a new case of this tumor. Thus, to the best of our knowledge, the present case represents only the 10th case of solid type PIOSCC arising in the maxilla to be reported.

Standard treatment for PIOSCC includes surgery, radiotherapy, or both, and the prognosis is relatively poor [2-7]. All reports strongly suggest that wide resection of the primary tumor with a sufficient safety margin [2-9]. However, no standard indications or protocols for radio- or chemoradiotherapy have been established. Additional study is needed to identify optimal treatment modalities.

\section{Consent}

Written informed consent was obtained from the patient for publication of this case report and any accompanying images. A copy of the written consent is available for review by the Editor-in-Chief of this journal.

\section{Competing interests}

The authors declare that they have no competing interests.

\begin{abstract}
Authors' contributions
$\mathrm{SI}$ and $\mathrm{NK}$ operated and monitored the patient. TK, MI, HO, HT, and HS assisted in the surgery and monitoring the patient. All authors read and approved the final manuscript.
\end{abstract}

\section{Author details}

'Division of Dentistry, Oral and Maxillofacial Surgery, Faculty of Medicine, Yamagata University, 2-2-2 lida Nishi, Yamagata City Yamagata 990-9585, Japan. ${ }^{2}$ Division of Plastic and Reconstructive Surgery, Faculty of Medicine, Yamagata University, 2-2-2 lida Nishi, Yamagata City Yamagata 990-9585, Japan.

Received: 21 August 2013 Accepted: 18 December 2013

Published: 31 December 2013

\section{References}

1. Barnes L, Eveson JW, Reichart P, Sidransky D, International Agency for Research on Cancer: Pathology and genetics of Head and neck tumors. Lyon: IARC: World Health Organization; 2005:290-291.

2. Suei $Y$, Tanimoto K, Taguchi A, Wada T: Primary intraosseous carcinoma: Review of the literature and diagnostic criteria. J Oral Maxillofac Surg 1994, 52:580-583.

3. Chaisuparat R, Coletti D, Kolokythas A, Ord RA, Nikitakis NG: Primary intraosseous odontogenic carcinoma arising an odontogenic cyst or de novo: a clinicopathologic study of six new cases. Oral Surg Oral Med Oral Pathol Oral Radiol Endod 2006, 101:194-200.

4. Thomas G, Panday M, Mathew A, Abraham EK, Francis A, Somanthan T, lype EM, Sebastian P, Nair MK: Primary intraosseous carcinoma of the jaw: pooled analysis of world literature and report of two new cases. Int J Oral Maxillofac Surg 2001, 30:349-355.

5. Lugakingira M, Pytynia K, Kolokythas A, Miloro M: Primary intraosseous carcinoma of the mandible; case report and review of the literature. J Oral Maxillofac Surg 2010, 63:2623-2629.

6. Huang JW, Luo HY, Li Q, Li TJ: Primary intraosseous squamous cell carcinoma of the jaws. Clinicopathologic presentation and prognostic factors. Arch Pathol Lab Med 2009, 133:1834-1840.

7. Nomura T, Monobe H, Tamaruya N, Kishihsita S, Saito K, Miyomoto R, Nakao K: Primary intraosseous squamous cell carcinoma of the jaw: two new cases and review of the literature. Eur Arch Otorhinolaryngol 2013, 270:375-379.

8. Eversole LR: Malignant epithelial odontogenic tumors. Semin Diagn Pathol 1999, 16:317-324.

9. Mohyuddin N, Yao M: Primary intraosseous carcinoma of the anterior maxilla: an unusual case and review of the literature. Ear Nose Throat J 2011, 90:E35-E37.

doi:10.1186/1472-6815-13-13

Cite this article as: lino et al:: Solid type primary intraosseous squamous cell carcinoma in the maxilla: report of a new case. BMC Ear, Nose and Throat Disorders 2013 13:13.

\section{Submit your next manuscript to BioMed Central and take full advantage of:}

- Convenient online submission

- Thorough peer review

- No space constraints or color figure charges

- Immediate publication on acceptance

- Inclusion in PubMed, CAS, Scopus and Google Scholar

- Research which is freely available for redistribution 